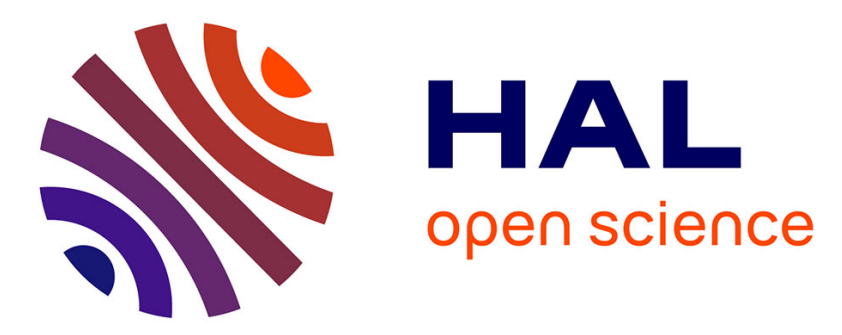

\title{
Psychiatric disorders and health service utilization in unemployed youth
}

Volker Reissner, Meike Rosien, Kai Jochheim, Olaf Kuhnigk, Hans Dietrich, Alfons Hollederer, Johannes Hebebrand

\section{- To cite this version:}

Volker Reissner, Meike Rosien, Kai Jochheim, Olaf Kuhnigk, Hans Dietrich, et al.. Psychiatric disorders and health service utilization in unemployed youth. Journal of Public Health, 2010, 19 (S1), pp.13-20. 10.1007/s10389-010-0387-x . hal-00615352

\section{HAL Id: hal-00615352 \\ https://hal.science/hal-00615352}

Submitted on 19 Aug 2011

HAL is a multi-disciplinary open access archive for the deposit and dissemination of scientific research documents, whether they are published or not. The documents may come from teaching and research institutions in France or abroad, or from public or private research centers.
L'archive ouverte pluridisciplinaire HAL, est destinée au dépôt et à la diffusion de documents scientifiques de niveau recherche, publiés ou non, émanant des établissements d'enseignement et de recherche français ou étrangers, des laboratoires publics ou privés. 
PSYCHIATRIC DISORDERS AND HEALTH SERVICE UTILISATION IN UNEMPLOYED YOUTH

V. Reissner, M. Rosien, K. Jochheim, O. Kuhnigk, H. Dietrich, A. Hollederer, J. Hebebrand

V. Reissner ( $\bowtie)$, M. Rosien, K. Jochheim

University of Duisburg-Essen,

Department of Child- and Adolescent Psychiatry and Psychotherapy

Virchowstr. 174

45147 Essen, Germany

Volker.reissner@uni-due.de

O. Kuhnigk

University of Hamburg, Clinic and Polyclinic for Psychiatry and Psychotherapy

Martinistr. 52

202046 Hamburg, Germany.

H. Dietrich

Institute for Employment Research

Regensburger Str. 104

90478 Nürnberg, Germany

Institute for Health and Employment

Westerfeldstr. 35/37

33611 Bielefeld, Germany 


\title{
PSYCHIATRIC DISORDERS AND HEALTH SERVICE UTILISATION IN UNEMPLOYED YOUTH
}

\begin{abstract}
Aim: Youth unemployment is associated with increased levels of anxiety, depression, alcohol abuse, reduced self-esteem and life-satisfaction. Up to date data based on standardized psychiatric diagnostic assessments in adolescent or young adult jobless is very scarce. To our knowledge this study for the first time assessed both Axis-I (non-personality) and Axis-II (personality) psychiatric disorders and related constructs in a preselected sample of unemployed.

Subjects and methods: Subjects were aged 16-24 and lived in the large urban region of Essen, Germany. They were referred by case managers of the vocational services centre to the on-site psychiatric out-patient unit. SCID-I and -II were administered to assess DSM-IV diagnoses. Symptom Checklist 90 R, Beck Depression Inventory and Client Sociodemographic Service Receipt Inventory were used to measure severity of psychopathology and health service utilization.

Results: $98 \%$ of unemployed young adults suffered from mental disorders. Mood and anxiety disorders were the most common Axis-I disorders (47.9\% and 33.4\%). 58.2\% of probands met diagnostic criteria for a personality disorder; a borderline personality disorder accounted for one half of these disorders. Despite a 49\%-rate of AxisI and II comorbidity and severe psychopathology the majority of subjects were untreated and mental health service utilisation in general was low. The diagnosis of a personality disorder was related to a 2.7 -fold risk to drop out of a job reintegration programme.

Conclusion: Unemployed young adults referred for a psychiatric assessment have a high rate of both Axis-I and II disorders, which need to be considered upon planning individual-based vocational rehabilitation programs.
\end{abstract}

Keywords: youth unemployment, mental health, personality disorder, health service utilisation, SUPPORT25

\section{Introduction}

Unemployment rates across Europe and the US are currently on the rise again. This is seen as a consequence of the 2008 financial market break-down and the consecutive stock market crisis plunging global markets and economies into recession. Especially adolescents and young adults are thought to be affected by such a development. As long-term youth unemployment fosters the different facets of social exclusion and increases 
costs for social security systems it is targeted by multiple programmes by the European Commission (Kieselbach 2003).

Cross-sectional studies show a close relationship between unemployment and poor general as well as mental health (e.g. Reim et al. 2009; Wang et al. 2005). Some longitudinal studies support the hypothesis that suffering from a mental health problem causes unemployment (selection or drift hypothesis; e.g. Dooley et al. 1994). Alternatively, individuals develop psychiatric disorders as a result of unemployment (social causation hypothesis). Mental health and unemployment are two interacting variables influenced by different individual and environmental features such as work involvement, appraisal of the situation, coping strategies and others (McKee-Ryan et al. 2005).

Many research designs focussing on unemployed merely targeted "psychological well-being" or psychological symptoms which are measured according to their frequency or severity using questionnaires. This approach is however not sufficient for the interpretation of the psychiatric status and clinical and therapeutic relevance and prognosis. In studies that included unemployed individuals of all ages, psychiatric symptoms and disorders diagnosed were depression (e.g. Stankunas et al. 2006), substance use (e.g. Hämäläinen et al. 2005; Mossakowski 2008) and suicidal behaviour (e.g. Morrell et al. 1993) among others. Single investigators have determined rates of Axis-I or non-personality disorders in both unemployment-specific (Claussen 1999 using DSM-III) or large non-specific epidemiological studies (e.g. Dooley et al. 1994 using DSM-III).

Unemployed young adults have been shown to have a higher risk for mental illness. In the limited number of psychiatric studies among this group, the major finding was an elevated rate of alcohol disorders (e.g. Claussen 1999). In one study (Fergusson et al. 2001) exposure to unemployment was significantly associated with suicidal ideation, substance abuse and criminal behaviours. Fergusson and colleagues (1997) demonstrated that unemployed at the age of 18 showed a higher prevalence of psychiatric disorders; higher rates for major depression, anxiety, conduct and substance use disorders were prevailing. Other Axis-I disorders and especially personality disorders were not examined in these as well as in other studies on young unemployed.

Adolescents and young adults are especially vulnerable to failure in the transition periods from adolescence to adulthood and from school to work (e.g. Hammer 1992). Evidently, non-integration into the job-market at a young age has profound long-term implications.

Hammarstrom and Janlert (2002) showed for a 14 year follow-up cohort that early unemployment among young men and women had a significant explanatory effect on smoking, alcohol use and anxiety as well as depressive symptoms. 
We are not aware of any studies that have determined both Axis-I and -II DSM-IV diagnoses. Particularly, the

lack of data pertaining to Axis-II or personality disorders (PD) merit consideration because such disorders begin in early adolescence (Beauchaine et al., 2009). Thus they may have a profound impact on job (re-) integration. Because of the particular relevance of psychiatric disorders for initial integration into the job market, we focussed on young unemployed aged 16 to 24.9 .

The goals of this analysis were to

- $\quad$ establish the prevalences of both DSM-IV Axis-I and II disorders in a sample of unemployed adolescents and young adults from a joint psychiatric and vocational counselling service,

- examine the level of symptom severity, psychopathology and psychosocial functioning,

- $\quad$ asses somatic and mental health service use and

- $\quad$ identify differences between probands with and without comorbid PD.

\section{Methods \\ Recruitment and eligibility}

In March 2007 an out-patient unit of the Department of Child and Adolescent Psychiatry of the University of Duisburg-Essen was established on the grounds of the vocational services centre Essen. This approach has proven successful to reintegrate unemployed with severe mental illness in a US-study (Cook et al. 2005). For the purpose of our study case managers of the vocational services centre referred clients who they deemed to require a psychiatric evaluation. Counsellors initially received training to identify psychiatric symptoms by professional mental health service staff. In addition they received case-related feedback throughout the study.

Clients from the vocational service centre Essen eligible for study entry had to

1. receive unemployment benefit,

2. be aged between 16.0 and 24.9 years,

3. suffer from self-reported (to the case manager) or deduced mental problems,

4. participate voluntarily (informed written consent). 
Between April 2007 and March 2008 diagnostic evaluation and counselling was recommended to 229 (55.5\% female) unemployed youth by case managers. Participation was voluntary; $15(6.6 \%)$ did not consent to their proposed referral. The others were consecutively admitted to the study. All clients were asked to attend four diagnostic and counselling sessions; at each time point diagnostic issues were addressed. 49 (21.4\%) subjects out of 229 attended the initial session only, and thus did not participate in the interviews scheduled for sessions 2-4. $165(72 \%)$ out of 229 probands who completed the diagnostic interviews were included in this analysis. For the questionnaires differences in sample size are due to missing data related to non-adherence to sessions 2-4.

Instruments

Structured face-to-face interviews were conducted including the following instruments:

(1) Sociodemographic and biographic information was assessed by the current version of the German Socio-Economic Panel Study (SOEP) Questionnaire. This instrument is issued by the German Institute for Economic Research (2007) and covers e.g. biographic data including social integration, childcare and level of education as well as current and past job status. Institutional upbringing was defined as living in an orphanage and/or foster family for at least one year before age 15. School truancy was defined as continuous absence from school for more than six days. Psychiatric treatment utilisation was assessed both prior to and after age 18 .

(2) A psychiatric disorder according to DSM-IV criteria was assessed via the administration of the Structured Clinical Interviews (SCID-I and SCID-II). The SCID-I is a semi-structured interview based on a decision tree approach to establish Axis-I diagnoses. The SCID-II detects (co-morbid) Axis-II disorders. Assessments of both PD and Non-PD are reliable (Williams et al. 1992).

(3) The Symptom Checklist-90-R (SCL-90-R; Derogatis et al. 1976) evaluates a broad range of psychological problems and symptoms of psychopathology. The Global Severity Index used for the purpose of this study represents overall psychological distress.

(4) The Beck Depression Inventory (BDI) was utilized to assess the severity of depressive symptoms. A cut-off score of $\geq 18$ classifies clinically relevant moderate to severe depressive syndromes. Reliability 
and validity have been demonstrated to be sufficient in clinical and non-clinical samples (Beck et al. 1988).

(5) The Client Socio-Demographic and Service Receipt Inventory (CSSRI; Chisholm et al. 2000): This instrument is feasible to collect standardized information on the patient's use of health, social, education and criminal justice services. The structured interview retrospectively tracks the subjects' contacts especially with medical and psychiatric services. The patient is asked which treatment units he visited and the frequency of use during the past three or six months.

(6) Apart from self-report inventories, interviewers rated severity of symptoms and psychosocial functioning:

The Global Assessment of Functioning (GAF; Endicott et al. 1976) as defined in the DSM-IV (Axis V) is used to measure the general level of psychological, social and occupational functioning of a subject. In this study the numeric scale from 0 to 100 represents the subject's state at intake interview. Low numbers indicate low psychosocial functioning and vice versa.

The Clinical Global Impression - Severity scale (CGI-S; Guy 1976) is useful to judge symptom severity. The clinician assesses the subject's state on a one-item, 7-point scale in relation to past clinical experience of patients suffering from the same diagnosis. Though CGI-S and GAF are criticized because of reliance on subjective judgments they are widely used and their validities for different disorders recognized (Soderberg et al. 2005).

Interviewers were one psychologist with a master's degree and one adult senior psychiatrist. They were appropriately trained to conduct the SCID I and II as well as the other questionnaires applied. Consensus diagnostic meetings were held every two weeks.

The study received approval by the Ethics Committee of the Medical School of the University Duisburg-Essen. Data-analysis for group differences were done by T-Test for continuously distributed variables or Mann-Whitney tests. $\chi^{2}$-tests were computed for dichotomous variables; the nominal $\mathrm{p}$-values were not corrected for multiple testing. A logistic regression was conducted and odds ratios (OR) and 95\% confidence intervals (95\% CI) were 
calculated to determine risk-factors for success or failure in job reintegration programs. All calculations were performed using the statistical program SPSS v. 14.0.

\title{
Results
}

Sociodemographic and biographic data

Among 165 subjects 96 (58.2\%) were female (Table 1). The unemployed young adults had a mean age of 21.4 years and were of German nationality (95.1\%). $46.8 \%$ of probands reported a history of school truancy. $76.1 \%$ had never been employed after finishing school. Subjects were on average 19.0 years $(\mathrm{SD}=2.24)$ when contacting vocational services because of unemployment for the first time. 163 reported on their vocational history: Between the date of registration as unemployed and inclusion into the study subjects achieved different levels of vocational reintegration as measured by the completion of job schemes. In the "Achievers-group" $12.3 \%$ completed all training schemes they were assigned to and $18.4 \%$ of subjects had finished at least one vocational reintegration course (total: $30.7 \%$ ). The "Under-achievers" consisted of $50.9 \%$ who did not complete any programme and $18.4 \%$ who did not commence any programme at all (total: $69.3 \%$ ).

\section{Insert Table 1 here}

Psychiatric morbidity

\begin{abstract}
Axis-I and Axis-II disorders: All percentages given refer to the 165 probands: We categorized the spectrum of psychiatric disorders into four groups: Axis-I disorders only (Non-PD; 40.0\%), Axis-II disorders only (PD-only; 8.5\%), and comorbid Axis-I and II disorders (49.1\%). Only 4 (2.4\%) subjects did not meet the criteria of any psychiatric disorder (Figure 1).
\end{abstract}

\section{Insert Figure 1 here}


Mood and Anxiety Disorders were the most common non-PD diagnoses (47.9\% and 33.4\%). $27.3 \%$ of the unemployed fulfilled the diagnostic criteria of substance abuse or dependence (alcohol and illegal drugs). 57.6\% of the sample suffered from one or more PD.

\section{Insert Figure 2 here}

$5.4 \%$ of the sample suffered from a cluster A PD (odd or eccentric disorders) and $34.5 \%$ from a cluster B PD (dramatic, emotional, or erratic disorders). $17.5 \%$ belonged to the group with anxious or fearful disorders (cluster C). The criteria for a borderline PD were met by $28.5 \%$ of the whole sample. The second largest group of personality disordered probands were diagnosed with avoidant PD (13.9\%; Table 2).

\section{Insert Table 2 here}

Axis-I and Axis-II disorders: A minimum of two disorders (Axes I and II combined) applied to the majority of subjects (107; 64.9\%). 29.7\% (49) of probands had at least three, 9.7\% (16) four or more disorders.

Only few differences in the prevalences of Axis-I disorders were found between those with any PD and those without PD (Table 3).

\section{Insert Table 3 here}

Dimensional assessment of psychopathology and psychosocial functioning: For all SCL-90-R subscales and the Global Severity Index the unemployed young adults self-reported high mean scores comparable to hospitalized psychiatric samples (e.g. Baron and Linden 2009). About two thirds of all clients (66.2\%; $n=154)$ had to cope with a clinically relevant depressive syndrome as measured by the BDI. In addition to these self-ratings, the interviewers perceived $56.9 \%$ of probands as at least "moderately ill" on the CGI-scale (CGI-Mean: 4.53, SD: 1.20). Psychosocial functioning was frequently impaired (GAF-Mean: 53.92, SD: 12,38). $41.2 \%$ of all subjects scored 50 or less due to serious symptoms or a serious impairment regarding social, occupational, or school functioning. Testing revealed that subjects with PD were more severely disturbed than those without (p-values < 
0.05). This pertains to SCL-90-R subscales, BDI, CGI and GAF (Table 4). Apart from current psychosocial functioning our biographic data show that individuals with the diagnosis of PD had achieved significantly lower school degrees compared to their Non-PD counterparts $(\mathrm{p}=0.032)$.

\section{Insert Table 4 here}

Health service use

Data from the SOEP- and CSSRI-Questionnaires show low treatment utilization. Prior to age $18,40.1 \%$ of subjects $(\mathrm{N}=147)$ had been in contact with psychiatric services at least once. After age 18 , this applied to 36.1\%. Probands with PD had contacted a psychiatrist or psychotherapist before and after 18 more often than those without PD ( $p=0.006$ and $p=0.20$ respectively). Recent health service use was low: In the six-monthperiod prior to the study 7 probands $(5.5 \%)$ had been treated in a psychiatric hospital or day clinic setting. Only $16(12.4 \%)$ had been in touch with a psychiatric or psychotherapeutic out-patient unit within the last three months; only half of these received more or less regular treatment. 12 probands $(9.3 \%)$ were currently taking psychoactive medication.

Risk factors for success or failure in job reintegration programmes

In the logistic regression model programme adherence was defined as the completion of at least one reintegration programme since the application for unemployment benefits ("Achievers") in contrast to those who had never engaged in or did not terminate any job scheme ("Under-achievers"). It was hypothesized that the variables gender, contact to psychiatric services before legal age, school truancy, number of years of institutional upbringing before age 16 and PDs serve as risk factors. The model terms were all present prior to the subjects' unemployment and his success or failure in job reintegration schemes. This pertains also to PDs which by definition already develop and show their effects in early adolescence (Grilo et al., 1998). Adolescent PD and PD in adulthood are similar with regard to structure (Westen et al., 2003), concurrent validity (Levy et al., 1999), and stability (Johnson et al., 2000). All terms were entered in one step. The resulting odds ratios were interpreted as the relative risk to experience major problems in job reintegration. 
A diagnosis of a PD emerged as the sole risk factor. Probands suffering from a PD showed a 2.7 fold increased risk of failure in a job scheme $(95 \% \mathrm{CI}=1.2-6.4)$. All other variables did not reach statistical significance (Table 5).

\section{Insert Table 5 here}

\section{Discussion}

The study showed a very high psychiatric morbidity (Axis-I and Axis-II) amongst a preselected sample of young unemployed adults. Especially personality disorders were the most prevalent diagnostic entity which predicted a high risk for failure in job (re)integration. Despite severely impaired mental and psychosocial functioning subjects were currently mostly not seeking treatment.

This is to our knowledge the first study to concomitantly asses Axis-I and Axis-II disorders in addition to both self and interviewer rated psychopathology and psychosocial functioning in unemployed individuals. Most of the previous aggregate and individual-panel-studies relied on self-reported symptom counts only. These measures do not differentiate between psychopathology in the normal range and clinically relevant disorders (Dooley et al. 1996). Studies exploring unemployment on a disorder-level were often restricted to single or few Axis-I disorders. Our data provide thorough insights into the situation of young unemployed adults who were referred to our psychiatric unit on the premises of the vocational services center of the city of Essen by the respective case managers.

Particularly noteworthy is the high rate of PD (58.2\%), especially the borderline (28.5\%) and avoidant (13.9\%) types. The prevalence of "any" PD in community surveys is between 4.4 to $13.0 \%$; the rates for borderline and avoidant PD are between 0.7 and $2.0 \%$ and 0.8 and 5.0\%, respectively (Coid 2003). In our study the diagnosis of one or more PD was associated with profound implications: These individuals had achieved significantly lower school degrees than their Non-PD counterparts. They showed a higher psychopathological loading and a poorer psychosocial functioning as assessed with SCL-90-R, BDI, CGI and GAF. In addition and importantly, the diagnosis of a PD entailed a 2.7 fold increased risk of not having commenced or completed a job integration programme of the vocational service centre. In one previous study classifying three broad categories of Axis-I- 
disorders, the 2-year-prevalences from 16 to 18 years were established in young long-term unemployed

(Fergusson et al. 1997). Compared to the present study Fergusson and colleagues found a similar ranking of prevalence rates placing substance abuse disorders ahead of anxiety disorders and major depression both of which showed similar prevalence rates.

PDs begin in adolescence and early adulthood and often interpersonal and social negative effects persist during life-span (Haw and Hawton 2008). During the transition from school to work life the existence of a PD may be relevant for the individual's vocational chances to become (re-) employed. Individuals with PD have significantly higher levels of psychopathological disturbance and social dysfunction compared to those suffering from an Axis-I disorders only. In the present study, the risk of an unemployed youth with PD either not to enter into the second labour market or to fail in a job-scheme or training-programme is about three times higher than for those without PD. The cross-sectional study design allows only for a conclusion about the association between low achievement and PD. We can not draw a conclusion on the causal pathways of unemployed with PDs regarding the selection vs. social-causation hypothesis (Dooley et al. 1994). The hypothesis that young adolescents in transition from school to work suffering from PDs have a higher risk for unemployment should be tested by a longitudinal study design.

As Axis-II disorders in this sample contributed to high severity scores in the questionnaires and to a negative outcome regarding the individuals vocational career, they should be discussed as confounding factors in the interpretation of other studies on unemployment and psychological well-being. Though we analysed a highly selected sample, our study clearly documents the importance of assessing PDs in psychiatric studies of young unemployed subjects.

Multiple comorbidity, severe psychopathology, maladaptive psychosocial behavior and poor job performance characterize this sample. Nevertheless, recent health service use, especially regarding psychiatric services is unexpectedly low. Most studies point out that health service use in general is assumed to be high in unemployed (Benavides et al. 1994), but these results pertain predominantly to somatic disorders and to adults in general. Drawing on Andersen's (1995) behavioral model of health services use several factors explaining low utilisation can be relevant. Particularly predisposing characteristics of the individual and apart from the mental disorder itself, stigma might be relevant especially for young adults. By contacting a psychiatrist or psychotherapist the proband has to cope with a second stigma in addition to unemployment (Jorm and Griffiths 2008; Alonso et al. 2008). Avoiding psychiatric diagnosis and treatment by not using mental health services potentially means avoiding reduced self-esteem (Link et al. 2008) and a lower risk of unemployment (Hinshaw and Stier 2008). Lack of sensitivity for mental health may also contribute to the low health care utilisation. Finally, treatment in 
outpatient services in Germany generally requires the payment of a surcharge of 10 euros due at the initial visit

to doctor's office every three months. For those living on unemployment benefit paying an "ordination fee" is a financial strain many often simply can not afford or will not accept. The introduction of this co-payment has reduced the number of outpatient-contacts. In the age group of those between 20 and 39 years first-contact rate was reduced by $16 \%$ compared to the status before the implementation of the fee (Brenner et al. 2007).

The major methodical limitation of our study pertains to the pre-selection of probands: The sample is highly selected and not representative for unemployed youth in general. Subjects were referred by case managers on the grounds of their judgement of psychological or psychosocial dysfunction resulting in unsuccessful reintegration efforts. In addition to a general pre-study training, each referred case was extensively discussed with the counsellor. A low rate of false positive referrals shows a high specifity of the case managers screening. Selfreported low psychological well-being and high failure rates in job reintegration schemes obviously were the main reasons to refer subjects. On the other hand nothing is known about the sensitivity of case managers in detecting less prominent or concealed psychiatric symptoms. Second, nonparticipation may also threaten the internal and external validity of the study. As most subjects have a long history of discontinuing reintegration programmes the initial refusal rate of $6.6 \%$ and the drop out rate over the four sessions of $22.9 \%$ is deemed acceptable. As a consequence the sample is not representative for the unemployed aged under 25 of the city of Essen (total population of 580.000). Nevertheless, we assume that our major findings of a very high rate of psychiatric disorders and particularly PD would hold up in a low-threshold psychiatric outpatient unit based at any vocational service centre in Germany.

Our findings foster the implementation of supported employment programmes for patients with (comorbid) PD as they already exist for patients suffering from schizophrenia (Burns et al. 2008). Similar evidence-based models should be adapted and introduced for PDs to improve the psychological and occupational-related wellbeing of young adults and to ameliorate their chances of job integration.

Conflict of interest The authors declare that they have no conflict of interest.

\section{References}

Alonso J, Buron A, Bruffaerts R, He Y, Posada-Villa J, et al. (2008) Association of perceived stigma and mood and anxiety disorders: results from the World Mental Health Surveys. Acta Psychiatrica Scandinavica 118:305-14 
Andersen RM (1995) Revisiting the behavioral model and access to medical care: does it matter? Journal of Health and Social Behavior 36:1-10

Baron S, Linden M (2009) Disorders of functions and disorders of capacity in relation to sick leave in mental disorders. International Journal of Social Psychiatry 55:57-63

Beck AT, Steer RA, Garbin MG (1988) Psychometric properties of the Beck Depression Inventory: 25 years of evaluation. Clinical Psychology Review 8:77 - 100

Benavides FG, Garcia AM, Sez-Lloret I, Librero J (1994) Unemployment and health in Spain: The influence of socio-economic environment. European Journal of Public Health 4:103- 7

Beauchaine TP, Klein DN, Crowell SE, Derbidge C, Gatzke-Kopp L (2009) Multifinality in the development of personality disorders: A Biology x Sex x Environment interaction model of antisocial and borderline traits. Dev Psychopathol 21:735-70

Brenner G, Koch H, Kerek-Bodden H, Heuer J, Lang A (2007) Diagnoses as the subject of health service research to analyse the morbidity of outpatients. Bundesgesundheitsblatt Gesundheitsforschung Gesundheitsschutz 50:1021-7

Burns T, Catty J, White S, Becker T, Koletsi M, et al. (2008) The Impact of Supported Employment and Working on Clinical and Social Functioning: Results of an International Study of Individual Placement and Support. Schizophrenia Bulletin Advance Access published April 21, 2008

Chisholm D, Knapp MR, Knudsen HC, Amaddeo F, Gaite L, van Wijngaarden B (2000) Client SocioDemographic and Service Receipt Inventory-European Version: development of an instrument for international research. EPSILON Study 5. European Psychiatric Services: Inputs Linked to Outcome Domains and Needs. Brithish Journal of Psychiatry Supplement 39:s28-33

Claussen B (1999) Alcohol disorders and re-employment in a 5-year follow-up of long-term unemployed. Addiction 94:133-8

Coid J (2003) Epidemiology, public health and the problem of personality disorder. British Journal of Psychiatry Supplement 44:S3-10

Collins P, Barker C (2009) Psychological help-seeking in homeless adolescents. International Journal of Social Psychiatry 55:372-84

Cook JA, Lehman AF, Drake R, McFarlane WR, Gold PB, et al. (2005) Integration of psychiatric and vocational services: a multisite randomized, controlled trial of supported employment. American Journal of Psychiatry 162:1948-56

Derogatis LR, Rickels K, Rock AF (1976) The SCL-90 and the MMPI: a step in the validation of a new selfreport scale. British Journal of Psychiatry 128:280-9

Dooley D, Catalano R, Wilson G (1994) Depression and unemployment: panel findings from the Epidemiologic Catchment Area study. American Journal of Community Psychology 22:745-65

Dooley D, Fielding J, Levi L (1996) Health and unemployment. Annual Review of Public Health 17:449-65

Endicott J, Spitzer RL, Fleiss JL, Cohen J (1976) The global assessment scale. A procedure for measuring overall severity of psychiatric disturbance. Archives of General Psychiatry 33:766-71

Fergusson DM, Horwood LJ, Lynskey MT (1997) The effects of unemployment on psychiatric illness during young adulthood. Psychologcial Medicine 27:371-81

Fergusson DM, Horwood LJ, Woodward LJ (2001) Unemployment and psychosocial adjustment in young adults: causation or selection? Social Science \& Medicine 53:305-20 
German Institute for Economic Research (2007) The German Socio-Economic Panel Study (SOEP)

Grilo CM, McGlashan TH, Quinlan DM, Walker ML, Greenfeld D, Edell WS. (1998) Frequency of personality disorders in two age cohorts of psychiatric inpatients. Am J Psychiatry 155:140-2

Guy W (1976) ECDEU Assessment Manual for Psychopharmacology. Rockville (MD): National Institute for Mental Health

Hamalainen J, Poikolainen K, Isometsa E, Kaprio J, Heikkinen M, et al. (2005) Major depressive episode related to long unemployment and frequent alcohol intoxication. Nordic Journal of Psychiatry 59:486-91

Hammarstrom A, Janlert U (2002). Early unemployment can contribute to adult health problems: results from a longitudinal study of school leavers. Journal of Epidemiology and Community Health 56:624-30

Hammer T, Vaglum P (1990) Use of alcohol and drugs in the transitional phase from adolescence to young adulthood. Journal of Adolescence 13:129-42

Haw C, Hawton K (2008) Life problems and deliberate self-harm: associations with gender, age, suicidal intent and psychiatric and personality disorder. Journal of Affective Disorders 109:139-48

Hinshaw SP, Stier A (2008) Stigma as related to mental disorders. Annual Review of Clinical Psychology 4:36793

Johnson JG, Cohen P, Kasen S, Skodol AE, Hamagami F, Brook JS (2000) Age-related change in personality disorder trait levels between early adolescence and adulthood: a community-based longitudinal investigation. Acta Psychiatr Scand 102:265-75

Jorm AF, Griffiths KM (2008) The public's stigmatizing attitudes towards people with mental disorders: how important are biomedical conceptualizations? Acta Psychiatrica Scandinavica 118:315-21

Kieselbach T (2003) Long-term unemployment among young people: the risk of social exclusion. American Journal of Community Psychology 32:69-76

Levy KN, Becker DF, Grilo CM, Mattanah JJ, Garnet KE, et al. (1999) Concurrent and predictive validity of the personality disorder diagnosis in adolescent inpatients. Am J Psychiatry 156:1522-8

Link B, Castille DM, Stuber J (2008) Stigma and coercion in the context of outpatient treatment for people with mental illnesses. Social Science \& Medicine 67:409-19

McKee-Ryan F, Song Z, Wanberg CR, Kinicki AJ (2005) Psychological and physical well-being during unemployment: a meta-analytic study. Journal of Applied Psychology 90:53-76

Morrell S, Taylor R, Quine S, Kerr C (1993) Suicide and unemployment in Australia 1907-1990. Social Science \& Medicine 36:749-56

Mossakowski KN (2008) Is the duration of poverty and unemployment a risk factor for heavy drinking? Social Science \& Medicine 67:945 - 55

Reime B, Jacob C, Wenzlaff P (2009) Is parental unemployment related to an increased risk for stillbirths? J Public Health 17:363 - 9

Soderberg P, Tungstrom S, Armelius BA (2005) Reliability of global assessment of functioning ratings made by clinical psychiatric staff. Psychiatric Services 56:434-8

Stankunas M, Kalediene R, Starkuviene S, Kapustinskiene V (2006) Duration of unemployment and depression: a cross-sectional survey in Lithuania. BMC Public Health 6:174 
Wang N, Iwasaki M, Otani T, Hayashi R, Miyazaki H, et al (2005) Perceived health as related to income, socio-

economic status, lifestyle, and social support factors in a middle-aged Japanese. Journal of Epidemiology 15:155-62

Westen D, Shedler J, Durrett C, Glass S, Martens A (2003) Personality diagnoses in adolescence: DSM-IV axis II diagnoses and an empirically derived alternative. Am J Psychiatry 160:952-66

Williams JB, Gibbon M, First MB, Spitzer RL, Davies M, et al (1992) The Structured Clinical Interview for DSM-III-R (SCID). II. Multisite test-retest reliability. Archives of General Psychiatry 49:630-6 


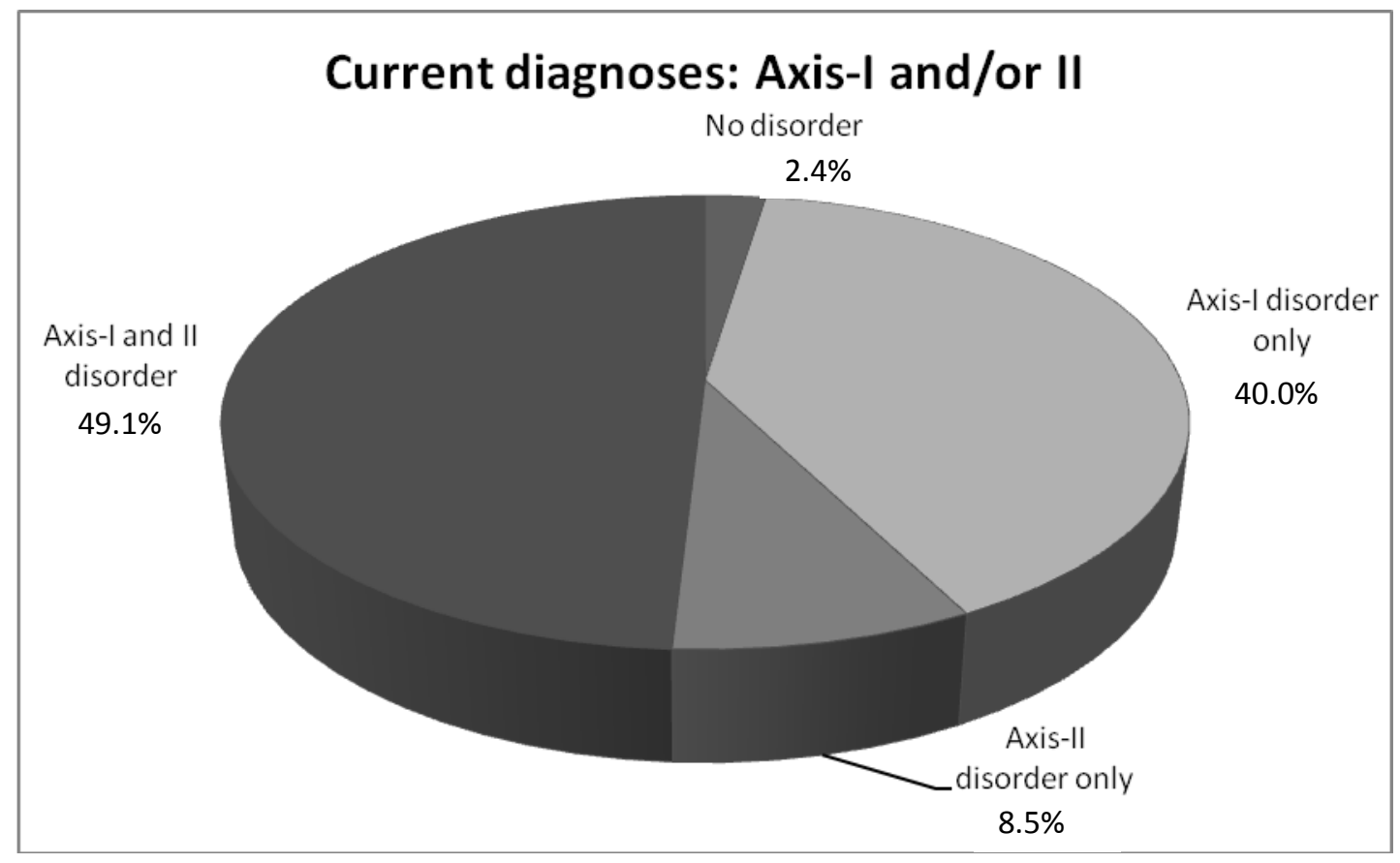

Fig. 1. Axis-I and Axis-II disorders

(Multiple diagnoses possible in 165 subjects; \% of patients) 


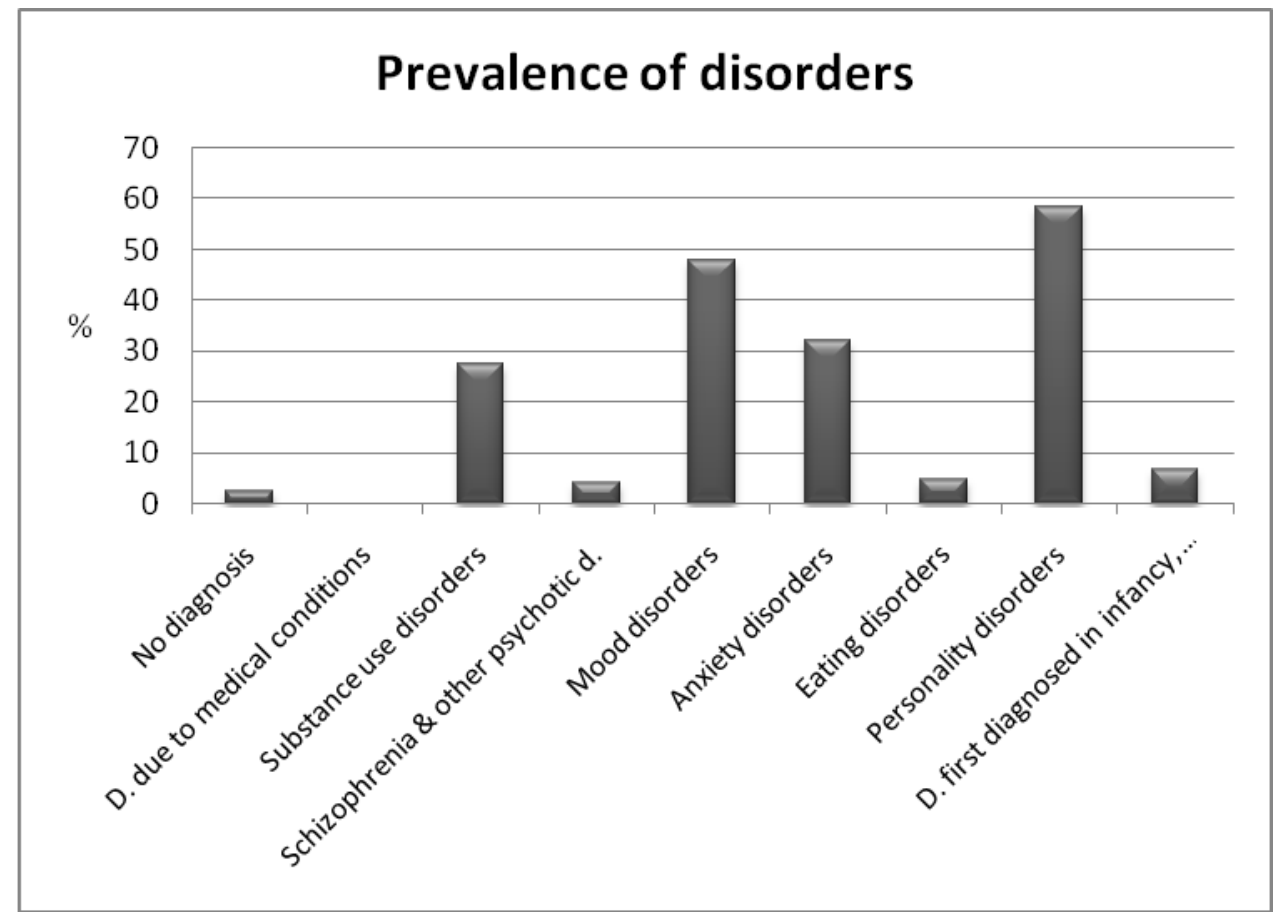

Fig. 2. Prevalence of disorders

(Multiple diagnoses possible in 165 subjects; \% of patients; D. - disorder) 
PSYCHIATRIC DISORDERS AND HEALTH SERVICE UTILISATION IN UNEMPLOYED YOUTH

Table 1. Sociodemographic and biographic data

\begin{tabular}{|c|c|c|c|}
\hline \multicolumn{2}{|l|}{ Variable } & $\mathbf{N}$ & $\%$ \\
\hline \multicolumn{2}{|l|}{ Age } & \multicolumn{2}{|c|}{21.4 years $(\mathrm{SD}: 2.1)$} \\
\hline \multicolumn{2}{|l|}{ Male } & 69 & $41.8 \%$ \\
\hline \multicolumn{2}{|c|}{ German nationality } & 156 & $95.1 \%$ \\
\hline \multicolumn{2}{|c|}{ Immigrational background $^{\mathrm{a}}$} & 42 & $26.6 \%$ \\
\hline \multicolumn{2}{|c|}{ Institutional upbringing } & 24 & $15.8 \%$ \\
\hline \multicolumn{2}{|c|}{ School truancy } & 65 & $46.8 \%$ \\
\hline \multicolumn{2}{|c|}{ School degree ${ }^{b}$ : None } & 71 & $45.8 \%$ \\
\hline & Low or medium & 72 & $46.5 \%$ \\
\hline & High & 12 & $7.7 \%$ \\
\hline \multicolumn{2}{|c|}{ Marital status: Never married } & 154 & $98.1 \%$ \\
\hline \multirow[t]{4}{*}{ Living status: } & Alone & 74 & $48.8 \%$ \\
\hline & With parents & 50 & $32.7 \%$ \\
\hline & With partner & 19 & $12.4 \%$ \\
\hline & Other & 10 & $6.5 \%$ \\
\hline \multicolumn{2}{|c|}{ Duration of unemployment } & 163 & 2.5 years $(\mathrm{SD}: 1.5)$ \\
\hline
\end{tabular}

${ }^{a}$ Immigrational background - At least one parent not born in Germany; ${ }^{b}$ School degree: High - High school or higher 
Table 2. Prevalence of personality disorders (multiple diagnoses possible in 165 subjects)

\begin{tabular}{lrr}
\hline Personality disorder & $\mathbf{N}$ & $\%$ \\
\hline Borderline PD & 47 & 28.5 \\
Avoidant PD & 23 & 13.9 \\
PD not otherwise specified & 8 & 4.8 \\
Narcissistic PD & 6 & 3.6 \\
Dependent PD & 5 & 3.0 \\
Paranoid PD & 4 & 2.4 \\
Schizoid PD & 4 & 2.4 \\
Antisocial PD & 4 & 2.4 \\
Histrionic PD & 4 & 2.4 \\
Schizotypal PD & 4 & 0.6 \\
Obsessive-Compulsive PD & 1 & 0.6 \\
\hline
\end{tabular}


Table 3. Prevalence of Non-PD amongst 165 unemployed young adults with and without personality disorder (multiple diagnoses possible)

\begin{tabular}{|c|c|c|c|c|c|c|}
\hline \multirow[t]{2}{*}{ Diagnosis } & & \multicolumn{2}{|c|}{ No PD } & \multicolumn{2}{|c|}{ Any PD } & \multirow{2}{*}{$\frac{\text { Total }}{\%}$} \\
\hline & & $\mathbf{n}$ & $\%$ & $\mathbf{n}$ & $\%$ & \\
\hline Substance related & Alcohol dependence / abuse & 6 & 3.6 & 14 & 8.5 & 12.1 \\
\hline disorders & $\begin{array}{l}\text { Substance dependence / } \\
\text { abuse }\end{array}$ & 11 & 6.7 & 18 & 10.9 & 17.6 \\
\hline Schizophrenia & Schizophrenia & 3 & 1.8 & 2 & 1.2 & 3.0 \\
\hline \multirow[t]{3}{*}{ Mood Disorders } & Minor Depression & 16 & 9.7 & 17 & 10.3 & 20.0 \\
\hline & Major Depression & 12 & 7.3 & 19 & 11.5 & 18.8 \\
\hline & Dysthymia & 7 & 4.2 & 10 & 6.1 & 10.3 \\
\hline \multirow[t]{7}{*}{ Anxiety Disorders } & Panic disorder & 3 & 1.8 & 3 & 1.8 & 3.6 \\
\hline & Agoraphobia & 5 & 3.0 & 3 & 1.8 & 4.8 \\
\hline & Social Phobia & 4 & 2.4 & 8 & 4.8 & 6.2 \\
\hline & $\begin{array}{l}\text { Generalized Anxiety } \\
\text { Disorder }\end{array}$ & 1 & 0.6 & 5 & 3.0 & 3.6 \\
\hline & Specific Phobia & 2 & 1.2 & 0 & 0 & 1.2 \\
\hline & $\begin{array}{l}\text { Obsessive-Compulsive } \\
\text { Disorder }^{\text {a }}\end{array}$ & 0 & 0 & 6 & 3.6 & 3.6 \\
\hline & Posttraumatic Stress Disorder & 3 & 1.8 & 8 & 4.8 & 6.6 \\
\hline \multirow[t]{2}{*}{ Eating disorders } & Anorexia nervosa & 1 & 0.6 & 2 & 1.2 & 1.8 \\
\hline & Bulimia nervosa & 1 & 0.6 & 3 & 1.8 & 2.4 \\
\hline
\end{tabular}

${ }^{\mathrm{a}}$ Chi2-test (two-tailed): $\mathrm{p}=0.03$ 
Table 4. Severity of Psychopathology and Psychosocial Functioning $(\mathrm{N}=164)$

\begin{tabular}{|c|c|c|c|c|c|}
\hline & \multirow{2}{*}{$\begin{array}{l}\text { No PD } \\
\text { Mean }\end{array}$} & \multirow{2}{*}{$\begin{array}{l}\text { Any } \\
\text { PD } \\
\text { Mean }\end{array}$} & \multirow[b]{2}{*}{$\mathbf{p}$} & \multicolumn{2}{|c|}{ Total } \\
\hline & & & & Mean & SD \\
\hline $\begin{array}{l}\text { SCL-90-R } \\
\text { Global Severity Index }\end{array}$ & 1.0 & 1.5 & 0.000 & 1.3 & 0.8 \\
\hline Beck Depression Inventory & 18.8 & 24.5 & 0.002 & 22.2 & 11.3 \\
\hline Clinical Global Impression-S & 4.1 & 4.8 & $0.001^{\mathrm{a}}$ & 4.5 & 1.2 \\
\hline $\begin{array}{l}\text { Global Assessment of } \\
\text { Functioning }\end{array}$ & 56.1 & 52.2 & 0.044 & 53.9 & 12.4 \\
\hline
\end{tabular}

T-Test; ${ }^{a}$ Mann-Whitney-Test 
Table 5. Logistic Regression Model of the Reintegration Programme Adherence

\begin{tabular}{|c|c|c|c|c|c|c|c|}
\hline Variable & B & SE B & Wald & Sig. & OR & \multicolumn{2}{|c|}{$95 \% \mathrm{CI}$} \\
\hline Gender & -0.095 & 0.415 & 0.052 & 0.820 & 0.910 & 0.403 & 2.052 \\
\hline $\begin{array}{l}\text { Any contact to psychiatric services } \\
\text { before age } 18\end{array}$ & -0.423 & 0.443 & 0.915 & 0.339 & 0.655 & 0.275 & 1.559 \\
\hline $\begin{array}{l}\text { Number of years in institutional } \\
\text { upbringing before age } 16\end{array}$ & -0.015 & 0.079 & 0.035 & 0.852 & 0.985 & 0.843 & 1.151 \\
\hline $\begin{array}{l}\text { School truancy } \\
\text { (> } 6 \text { consecutive days) }\end{array}$ & -0.030 & 0.413 & 0.005 & 0.943 & 0.971 & 0.432 & 2.183 \\
\hline $\begin{array}{l}\text { Diagnosis: } \\
\text { Personality Disorder }\end{array}$ & 1.002 & 0.432 & 5.379 & 0.020 & 2.722 & 1.168 & 6.346 \\
\hline
\end{tabular}

$\mathrm{N}=114 ;$ Nagelkerke $\mathrm{R}^{2}=0.072$ 